\title{
Clinicopathological evaluation of postmenopausal bleeding in rural hospital set up
}

\author{
Astha Ubeja ${ }^{1 *}$, Amreen Singh ${ }^{2}$
}

\begin{abstract}
${ }^{1}$ Department of Obstetrics and Gynecology, Prakash Ubeja Super Speciality Hospital, Indore Road Khandwa, Madhya Pradesh, India

${ }^{2}$ Department of Obstetrics and Gynecology, Jaypee Hospital, Delhi, India
\end{abstract}

Received: 04 June 2017

Accepted: 29 June 2017

*Correspondence:

Dr. Astha Ubeja,

E-mail: asthanix@gmail.com

Copyright: ( ) the author(s), publisher and licensee Medip Academy. This is an open-access article distributed under the terms of the Creative Commons Attribution Non-Commercial License, which permits unrestricted non-commercial use, distribution, and reproduction in any medium, provided the original work is properly cited.

\section{ABSTRACT}

Background: Postmenopausal bleeding should be completely assessed to ensure the absence of malignancy and to identify and treat high risk patients such as those with endometrial hyperplasia. The aim of present study was to investigate the clinical significance and endometrial pathology in patients with postmenopausal bleeding.

Methods: A cross sectional study was carried on 100 patients with postmenopausal bleeding visiting Acharya Vinobha Bhave rural hospital, Sawangi between August 2009-December 2011. Patients were evaluated according to pelvic ultrasound, fractional curettage and endometrial histology.

Results: The incidence of postmenopausal bleeding was maximum between 51-60 years (48\%), the incidence of malignancy was $39 \%$, out of which carcinoma cervix was the commonest. In benign causes, dysfunctional uterine bleeding and prolapse with decubitus ulcer were the commonest. The histopathological evaluation suggested proliferative endometrium (25.64\%), atrophic endometrium (34.61\%) atypical endometrium (7.69\%) adenocarcinoma (7\%). On ultrasound, commonest finding was increased endometrial thickness $>4 \mathrm{~mm}$.

Conclusions: Carcinoma of genital tract is one of the important cause of postmenopausal bleeding, so early detection of the causes can be life-saving. Fractional curettage gives a better diagnosis of the causes of postmenopausal bleeding.

Keywords: Endometrial thickness, Histopathology, Postmenopausal bleeding

\section{INTRODUCTION}

PMB occurs in approximately $10 \%$ of postmenopausal women. ${ }^{1}$ WHO had defined postmenopausal bleeding as, An episode of bleeding twelve months or more after the last menstrual period. Seventy percent of cases of postmenopausal bleeding have harmless cause of bleeding but $30 \%$ of them are associated with malignancy.

According to the Indian cancer registry, there is an increasing trend for corpus uteri malignancies in the past 2 decades. Hence postmenopausal bleeding requires a thorough evaluation clinically and pathologically to exclude carcinoma as the cause and ensure a benign pathology. Carcinoma of genital tract is one the most important cause of postmenopausal bleeding. ${ }^{2}$

About $90 \%$ of patients with endometrial cancer present with postmenopausal bleeding. However, $10 \%$ of patients with postmenopausal bleeding have endometrial cancer. ${ }^{3}$ The current study was carried out to evaluate various causes of postmenopausal bleeding based on histopathology, and the percentage of various benign, premalignant and malignant endometrial and cervical lesions in post-menopausal bleeding. 


\section{METHODS}

This study was a cross sectional study, conducted in the Department of Obstetrics and Gynecology in collaboration with Pathology and Radiology Deparment in Acharya Vinobha Bhave Rural hospital Sawangi over a period of 15 months in august 2008 and October 2010. All new patients with bleeding after one or more years of menopause were included in the study.

Patients on hormone therapy, premature menopause, on anticoagulants were not included in the group. A detailed general history and menstrual history was recorded including age of menarche and duration of menopause. Complete general and systemic examination was performed. Relevant blood investigations were performed, if there was suspicious area colposcopy was done along with biopsy.

Transvaginal USG was done to note the endometrial thickness. Cervical cytology from squamocolumnar junction was taken, except for cervical cancer and prolapse fractional curettage was done in all patients after consent. First the endocervical curettage was obtained, then anterior wall posterior wall right lateral, left lateral and fundus. The amount and type of endometrium noted, the material preserved in $10 \%$ formalin and histopathological examination using hematoxylin and eosin was performed.

\section{RESULTS}

Figure 1 shows distribution of study subjects according to their age of postmenopausal bleeding. It was observed that maximum number of cases $29(29 \%)$ were in age group of 46-50 years. Mean age was 54.51.

$31 \%$ Study subjects had menopause between the age of $40-55$ years, $12 \%$ had menopause $51-55$ years. Only one patient had delayed menopause. Mean age of menopause was 46.99 years.

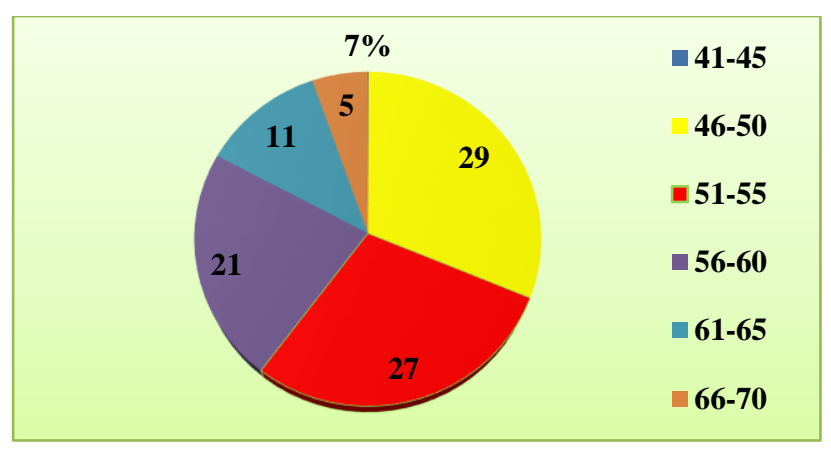

Figure 1: Distribution according to age.

Table 1 shows distribution of study subjects according to duration of menopause. This table also shows that as duration of menopause increases the incidence of postmenopausal bleeding decreases.

Mean duration of menopause was 7.20 years.

Table 1: Distribution of study subjects according to duration of menopause.

\begin{tabular}{|lll|}
\hline Years & No. of study subjects & $\%$ \\
\hline $1-4$ & 37 & 37 \\
\hline $5-8$ & 25 & 25 \\
\hline $9-12$ & 18 & 18 \\
\hline $13-16$ & 16 & 16 \\
\hline $17-20$ & 3 & 3 \\
\hline$>20$ & 1 & 1 \\
\hline & 100 & 100 \\
\hline
\end{tabular}

In 22 cases of carcinoma cervix endometrium could not be sampled. In 17 cases of prolapse uterus with decubitus ulcer endometrium was studied after hysterectomy.

Atrophy was most common histological diagnosis followed by proliferative (25.64\%). Atypical hyperplasia and adenocarcinoma had the same incidence. In 2 subjects, the sample was insufficient.

Table 2: Distribution of study subjects according to histological diagnosis in relation to endometrial thickness.

\begin{tabular}{|lllll|llll|}
\hline Histological diagnosis & $\mathbf{4} \mathrm{mm}$ & $\mathbf{5 - 1 0} \mathrm{mm}$ & $\mathbf{1 1 - 1 5} \mathrm{mm}$ & $\mathbf{1 6 - 2 0 \mathrm { mm }}$ & $\mathbf{2 1 - 2 5} \mathbf{m m}$ & $\mathbf{7 2 5} \mathrm{mm}$ & Total & $\%$ \\
\hline Insufficient sample & 2 & & - & - & - & - & 2 & 2.57 \\
\hline Atrophy & 27 & & - & - & - & & 27 & 34.61 \\
\hline Proliferative & 6 & 10 & 2 & 1 & - & $1-$ & 20 & 25.64 \\
\hline Secretory & - & 07 & 1 & 2 & - & - & 10 & 12.82 \\
\hline Polyp & - & - & 1 & 1 & - & - & 2 & 0.57 \\
\hline Simple hyperplasia & - & 01 & 4 & - & - & - & 5 & 6.41 \\
\hline Atypical endometrium & - & - & 2 & 4 & - & - & 6 & 7.69 \\
\hline Adenocarcinoma & - & 01 & - & 3 & 2 & - & 6 & 7.60 \\
\hline Total & 35 & 19 & 11 & 11 & 2 & 1 & 78 & 100 \\
\hline
\end{tabular}


Table 3: Distribution of study subjects according to benign causes of postmenopausal bleeding.

\begin{tabular}{|c|c|c|}
\hline Causes & $\begin{array}{l}\text { No. of study } \\
\text { subjects }\end{array}$ & $\%$ \\
\hline Prolapse with decubitus ulcer & 17 & 27.87 \\
\hline Dub & 17 & 27.87 \\
\hline Fibroid & 13 & 21.31 \\
\hline Adenomyosis & 7 & 11.48 \\
\hline Ovarian tumor & 1 & 1.64 \\
\hline Fibroid polyp & 2 & 3.38 \\
\hline Cervicitis with senile vaginitis & 1 & 1.64 \\
\hline \multirow[t]{2}{*}{ Cervical mucous polyp } & 3 & 4.92 \\
\hline & 61 & 100 \\
\hline
\end{tabular}

Table 3 shows the distribution of study subjects according to benign causes of postmenopausal bleeding. It was observed that prolapse with decubitus ulcer and dysfunctional uterine bleeding were the commonest benign conditions associated with postmenopausal bleeding 17 cases each.

Table 4: Distribution of study subjects according to malignant causes of postmenopausal bleeding.

\begin{tabular}{|lll|}
\hline Causes & No. of study subjects & $\%$ \\
\hline Carcinoma cervix & 25 & 64.10 \\
\hline Atypical endometrium & 6 & 15.38 \\
\hline Adenocarcinoma & 6 & 15.38 \\
\hline Ovarian cancer & 2 & 5.13 \\
\hline Total & 39 & 100 \\
\hline
\end{tabular}

Table 4 shows the distribution of study subjects according to malignant causes. Carcinoma cervix was the most common among the malignant causes (64.10\%) followed by atypical endometrium, adenocarcinoma and then ovarian tumours.

\section{DISCUSSION}

Postmenopausal bleeding is defined as any bleeding from the female genital tract in the appropriately aged woman, not using hormonal therapy for at least six months after cessation of menstruation or acyclical vaginal bleeding in a postmenopausal woman using hormonal therapy. ${ }^{4}$ Postmenopausal bleeding is one of the most important geriatric health problem as it alarms about genital malignancy, although $90 \%$ cases have benign cause of postmenopausal bleeding.

\section{Age}

In the present study, the age range was 41-70 years. It was observed that maximum number of cases i.e; $29 \%$ were in age group of 46-50 years and minimum in 66-70 years i.e; $5 \%$. Mean age was 54.51 years (Figure 1). In other study by Lidor et al 226 postmenopausal bleeding cases and revealed that the ages of patients ranged from 40-81 years with a mean of 56 years. ${ }^{4}$

\section{Duration of menopause}

The duration of menopause in years was calculated by taking time interval between onset of menopause and onset of postmenopausal bleeding .in the present study maximum number of study subjects $37 \%$ had duration of menopause between 1-4 years, followed by $25 \%$ between 5-8 years. $18 \%$ between $9-12$ years, $16 \%$ between $13-16$ years and 3\% between 17-20 years and only one case i.e. $01 \%$ had duration more than 20 years. Mean duration of menopause was 7.20 years (Table 4). Agrawal et al in their study revealed that in maximum percentage of cases that is $55.33 \%$ had duration of menopause $1-5$ years. $^{5}$

\section{Risk factors}

In a study by Nirupama $\mathrm{V}$ et al risk factors of the patients with PMB like obesity, hypertension and diabetes were $45 \%, 36 \%$ and $13 \%$ respectively. ${ }^{6}$ In present study hypertension and diabetes were most common with carcinoma of endometrium $(33 \%)$ and $20 \%$ in carcinoma cervix. According Syeda et al to the most frequently observed medical co-morbidity was obesity as $(72.7 \%)$ of the patients diagnosed as having carcinoma endometrium were obese $\left(\mathrm{BMI}>29 \mathrm{~kg} / \mathrm{m}^{2}\right){ }^{7}$

\section{Histopathological correlation with endometrial thickness}

In our study, histological diagnosis of endometrium was correlated with endometrial thickness in 78 cases. In 22 cases of carcinoma cervix endometrium could not be studied. It was observed that in $27(34.61 \%)$ cases of atrophy, endometrial thickness was $<4 \mathrm{~mm}$. Out of 20 $(25.64 \%)$ cases of proliferative endometrium 10 cases had endometrial thickness of $6-10 \mathrm{~mm}, 2$ cases had thickened $11-15 \mathrm{~mm}, 1$ case had $16-20 \mathrm{~mm}$, in 1 case it was more than $25 \mathrm{~mm}$ and in only in cases endometrial thickness was less or equal to $5 \mathrm{~mm}$. In a study done by Kothapallyk et al it was observed that women with a thick endometrial thickness $>4 \mathrm{~mm}$ are at risk of endometrial carcinoma. ${ }^{8,9}$ According to Rita et al most common causes for postmenopausal bleeding are endometrial hyperplasia $(40 \%)$, atrophic endometrium $(31 \%)$, isthmic endometrium $(5 \%)$, polyp $(5 \%)$, proliferative endometrium (13\%) and endometrial carcinoma $(6 \%) .{ }^{10}$

\section{Clinical diagnosis}

In our study prolapse with decubitus ulcer and dysfunctional uterine bleeding were the commonest benign conditions associated with postmenopausal bleeding i.e. $17(27.87 \%)$ cases each. The next common cause was fibroid uterus followed by adenomyosis. In present study, out of 30 cases of malignancy, Carcinoma cervix was the commonest malignant cause i.e. 25 $(64.10 \%)$, other causes were Adenocarcinoma and Ovarian cancer. Ghazi et al $(11.1 \%)$ which showed carcinoma cervix as the most common malignancy in 
PMB patients. ${ }^{11}$ According to Pragati et al benign conditions were seen in $206(82.4 \%)$ cases which included atrophic endometrium, proliferative endometrium, secretory endometrium, benign endometrial polyp, leiomyoma, tuberculous endometritis and simple cystic hyperplasia cases. Premalignant conditions such as hyperplasia with atypia seen in 18 (7.2\%). The malignant conditions seen were endometrial adenocarcinoma, cervical squamous cell carcinoma and Mixed Mullerian tumor in $26(10.4 \%)$ patients. ${ }^{12}$

\section{CONCLUSION}

With increased life span the incidence of postmenopausal bleeding is on rise. Since the incidence of malignancy is quite high, any bleeding in that age group should be evaluated in the line of malignancy unless otherwise proved. Patient characteristics like nulliparity hypertension, diabetes mellitus obesity etc should be considered. Women with an endometrial thickness $>4 \mathrm{~mm}$ or a histopathology showing a proliferative at the initial assessment are at risk of malignancy. Though the main aim of evaluation of cases of postmenopausal bleeding is to exclude premalignant and malignant lesions of the endometrium, majority of cases had benign causes for postmenopausal bleeding. Thus, postmenopausal bleeding is a symptom of varied etiologies and is not always because of malignant conditions. Therefore, careful histologic examination to find benign, premalignant and malignant lesions should be emphasized. Accurate diagnosis makes it much easier to counsel the patient about further course of management.

Funding: No funding sources

Conflict of interest: None declared

Ethical approval: The study was approved by the Institutional Ethics Committee

\section{REFERENCES}

1. Rossouw JE, Anderson GL, Prentice RL. Risks and benefits of estrogen plus progestin in Healthy postmenopausal women: principal results from the Women's Health Initiative randomized controlled trial. JAMA. 2002;288:321.
2. Cheema SZ, Saeed R, Ikram M. Postmenopausal bleeding. Professional Med J. 2008;15(3):328-34.

3. Wong SF, Luk KL, Wong AY, Tang LC. Finding in the women with postmenopausal bleeding investigated with hysteroscopy. J Obstet Gynaecol. 2001;21(4):392-5.

4. Lidor A, Ismajovich B, Confino E, David MP. Histopathological findings in 226 women with postmenopausal uterine bleeding. Acta Obstet Gynecol Scand. 1986;65:41-3.

5. Agrawal L, Fusey S. Role of vaginal scan ofor endometrial thickness in postmenopausal bleeding. Thesis (M.D.obs gynae) Nagpur university, Nagpur 1997.

6. Nirupama V, Suneetha Y, Prabha Devi K. Postmenopausal bleeding: an analytic study of 100 cases. Int J Sci Res. 2015;4:2588-90.

7. Fatima SS, Naib JM, Sharafat Z, Mazhar T. Postmenopausal bleeding-an alarming symptom of endometrial carcinoma. J Med Sci. 2014;22(4):166170.

8. Jillani K, Bahadur RK, Maqsood SA. Prevalence of malignant Disorder in 50 cases of postmenopausal bleeding. J Pak Med AssoC. 2010;60:540.

9. Kothapally K, Bhashyakarla U. Postmenopausal bleeding: clinicopathologic study in a teaching hospital of Andhra Pradesh. Int J Reprod Contracept Obstet Gynecol. 2013;2(3):344-8.

10. Rita D, Sunil Kumar KS, Rithesh SK. The clinicopathological study of postmenopausal bleeding. Int J Reprod Contracept Obstet Gynecol. 2016;5(11):3671-4.

11. Ghazi A, Jabbar S, Siddiqui N. Frequency of Endometrial carcinoma in patients with postmenopausal bleeding. Pak J Surg. 2005;21:41-4.

12. Karmarkar PJ, Wilkinson A, Rathod M. Histopathological evaluation of postmenopausal bleeding. IOSR-J Dent Med Sci. 2014;13(10):53-7.

Cite this article as: Ubeja A, Singh A.

Clinicopathological evaluation of postmenopausal bleeding in rural hospital set up. Int J Reprod Contracept Obstet Gynecol 2017;6:3556-9. 